\title{
Outcome of intrauterine adhesion management at a Nigerian tertiary hospital: a five-year review
}

\author{
R. O. Opadiran, A. D. Isah*, E. T. Agida, N. Adewole
}

Department of Obstetrics and Gynecology, University of Abuja Teaching Hospital Abuja, Nigeria

Received: 09 December 2017

Accepted: 08 January 2018

\section{*Correspondence:}

Dr. A. D. Isah,

E-mail: denisanthonyisah@yahoo.com

Copyright: (C) the author(s), publisher and licensee Medip Academy. This is an open-access article distributed under the terms of the Creative Commons Attribution Non-Commercial License, which permits unrestricted non-commercial use, distribution, and reproduction in any medium, provided the original work is properly cited.

\begin{abstract}
Background: Intrauterine adhesion is a cause of menstrual abnormalities and infertility, which are leading complaints in gynaecological practice in Nigeria. Determining the aetiology and management option would help reduce this problem. The objective of this study was to determine the aetiology, mode of presentation, management option and outcome of intrauterine adhesions

Methods: A retrospective analysis of intrauterine adhesions at the University of Abuja Teaching Hospital over a fiveyear period from 2012 to 2016 was carried out. The case notes of the patients were retrieved from the records department and information extracted from these case notes using a questionnaire included the age, level of education, marital status, parity, complaints, predisposing factors, method of diagnosis, treatment method and outcome. Additional information was obtained from the theatre registered. The least follow up period was one year.

Results: There were 82 patients diagnosed with Intrauterine Adhesion over the study period giving an incidence of $1.6 \%$. Fifty-nine case notes were available for analysis. The case note retrieval rate was $72 \%$. Majority of the patients were between the age range of 30-34 years $(21,35.6 \%)$. Those with tertiary level of education constituted the majority $(34,57 \%)$. Nullipara constituted $54.2 \%$ (32) of the total population. Menstrual abnormalities were the most common complaint with $93.2 \%$ and this includes those with menstrual abnormalities and other complaints. The commonest predisposing factor identified was a history of dilatation and curettage or uterine evacuation $(28,47.5 \%)$. Majority of the patients had partial intrauterine adhesions $(51,86.4 \%)$. All patients were treated with adhesiolysis, Foleys catheter insertion and hormonal therapy for 3 cycles. There was not statistical significance between those who had blind adhesiolysis and hysteroscopic adhesiolysis in terms of outcome. Restoration of menstrual flow was in $25,(42.4 \%)$ while $3,(5.1 \%)$ had miscarriges and an equal no of patients had term delivery.

Conclusions: Dilatation and curettage is still a major predisposing factor in the development of intrauterine Adhesions. Blind adhesiolysis still has its place in the management of intrauterine adhesion in developing countries.
\end{abstract}

Keywords: Aetiology, Intrauterine adhesion, Management, Outcome

\section{INTRODUCTION}

Intrauterine adhesion also known as "uterine synechiae" or Asherman's syndrome is a condition characterized by the presence of adhesion or scar tissue within the uterine cavity which prevents normal growth of the endometrium. ${ }^{1,2}$ It was first described in 1894 by
Heinrich Fritsch, it was only after 54years that a full description of Asherman's syndrome was carried out by an Isreali Gynaecologist Joseph Asherman. ${ }^{1}$

Its true incidence is unknown, but it was shown to occur in about $20 \%$ of patients being treated for infertility and $1.73 \%$ of new patients seen in Gynaecology clinic. ${ }^{3-6}$ An 
incidence of $1.3 \%, 4.7 \%$ and $6.7 \%$ has been reported from Ilorin, Lagos and Jos. ${ }^{7-9}$

The condition is usually caused by trauma to the basalis layer of the endometrium which is almost always related to a pregnancy event or following infection. ${ }^{10,11}$ Dilatation and curettage of a recently pregnant uterus is a common aetiology of IUA in developing countries as well as Puerperal sepsis, schistosomiasis and genital tuberculosis. ${ }^{1,12,13}$ Other aetiologic factors include curettage three to four weeks postpartum, during lactation or for septic or missed abortion, caesarean section, myomectomy, pelvic inflammatory disease and diagnostic curettage or pelvic irradiation., ${ }^{1,13,14}$

Common presenting features of Asherman's syndrome include menstrual irregularities, recurrent pregnancy loss and infertility. ${ }^{12,15}$ Other patients may have relatively normal menses in which a high index of suspicion is needed to make a diagnosis. ${ }^{13}$

Even though hysterosalpingography is the commonest method of diagnosis, hysteroscopy remains the mainstay of diagnosis and treatment. ${ }^{12,13}$ Other methods of diagnosis include saline infusion sonography, 3-D ultrasound scanning and magnetic resonance imaging. ${ }^{13,16,17}$

The aim of treatment is to restore the size and shape of the uterine cavity in order to restore endometrial/ menstrual function and to make pregnancy achievable. ${ }^{11}$ The treatment outcome however depends on the extent of the adhesions based on the hysterosalpingographic or hysteroscopic findings. ${ }^{11,18-20}$

This study is aimed at finding out the common aetiology of this condition and if there is any difference in outcome in patients managed by blind or hysteroscopic adhesiolysis in our hospital.

The objectives of this study were to determine the predisposing factors, mode of presentation, management and outcome of intrauterine adhesions.

\section{METHODS}

A retrospective analysis of patients with intrauterine adhesions managed at the University of Abuja Teaching Hospital from 2012 to 2016 was carried out.

The case notes of the patients were retrieved from the records Department and information extracted from these case notes using a questionnaire included the age, level of education, marital status, parity, complaints, predisposing factors, method of diagnosis, treatment method and outcome.

Additional information was obtained from the theatre registered. The outcome of treatment looked for included normalization of menses and pregnancy rate.
The data extracted was analyzed using SPSS version 20. Chi square was used for test of association. $\mathrm{P}<0.05$ was considered statistically significant.

\section{RESULTS}

Over the five-year period, there were 5,215 gynaecological cases that presented to the hospital. There were 82 patients diagnosed with intrauterine adhesion over the study period giving an incidence of $1.6 \%$. Fiftynine case notes were available for analysis. The case note retrieval rate was $72 \%$.

Table 1: Socio-demographic characteristics of patients with intrauterine adhesion.

\begin{tabular}{|lll|}
\hline Age range & $\begin{array}{l}\text { Frequency } \\
(\mathbf{n = 5 9})\end{array}$ & $\begin{array}{l}\text { Percentage } \\
(\%)\end{array}$ \\
\hline $20-24$ & 2 & 3.4 \\
\hline $25-29$ & 18 & 30.5 \\
\hline $30-34$ & 21 & 35.6 \\
\hline $35-39$ & 16 & 27.1 \\
\hline$>40$ & 2 & 3.4 \\
\hline Total & 59 & 100.0 \\
\hline Marital status & & \\
\hline Married & 50 & 84.7 \\
\hline Single & 9 & 15.3 \\
\hline Total & 59 & 100.0 \\
\hline $\begin{array}{l}\text { Educational } \\
\text { status }\end{array}$ & & \\
\hline Primary & 3 & 5.1 \\
\hline Secondary & 22 & 37.3 \\
\hline Tertiary & 34 & 57.6 \\
\hline Total & 59 & 100.0 \\
\hline
\end{tabular}

There were more cases within the age range of 30-34 years $(21,35.6 \%)$ and least in women between the ages of 20-24 years and those greater than 40 years $(2,3.4 \%)$ respectively as shown on the Table 1 . Majority of the women at presentation were married $(50,84.7 \%)$ and most had some tertiary level of education $(34,57.6 \%)$.

Table 2: Parity distribution.

\begin{tabular}{|lcl|}
\hline Parity & Frequency & Percentage $(\%)$ \\
\hline 0 & 32 & \\
\hline 1 & 17 & 54.2 \\
\hline 2 & 10 & 28.8 \\
\hline Total & 59 & 16.9 \\
\hline Miscarriages & $\mathbf{n = 5 9}$ & 100.0 \\
\hline 0 & 26 & \\
\hline 1 & 8 & 44.8 \\
\hline 2 & 11 & 13.8 \\
\hline 3 or more & 13 & 19.0 \\
\hline Total & 59 & 22.4 \\
\hline
\end{tabular}

Table 2 shows that 32 women from the population were nulliparous women constituting $54.2 \%$, while 26 of them 
(44.8\%) had no history of miscarriage at presentation, 13 $(22.4 \%)$ of them had three or more miscarriages.

Menstrual abnormalities were the most common presenting complaints contributing more than $90 \%$ with hypomenorrhoea as the major menstrual abnormality. Most patients that complained of inability to conceive also suffered from associated menstrual abnormality. However, only $6.8 \%$ had presenting complaint of infertility alone (Table 3 ).

Table 3: Presenting complaints.

\begin{tabular}{|lll|}
\hline Complaints & Frequency & Percentage \\
\hline Menstrual abnormalities & 32 & 54.2 \\
\hline Infertility & 4 & 6.8 \\
\hline $\begin{array}{l}\text { Menstrual abnormalities } \\
\text { with Infertility }\end{array}$ & 23 & 38.9 \\
\hline Total & 59 & 100.0 \\
\hline
\end{tabular}

The most common risk factor identified as shown on Table 4 was a history of dilatation and curettage, which was present in 28 women constituting $47.5 \%$. Caesarean section was a major risk factor for obstetric patients (12, $20.3 \%$ ). Manual removal of the placenta and pelvic surgery were the least identifiable risk factors for intrauterine adhesion $(1,1.7 \%)$.

Table 4: Risk factors.

\begin{tabular}{|lll|}
\hline Risk factors & Frequency & Percentage \\
Dilatation and curettage & 28 & 47.5 \\
\hline $\begin{array}{l}\text { Casearean section } \\
\begin{array}{l}\text { Pelvic inflammatory } \\
\text { disease }\end{array}\end{array}$ & 12 & 20.3 \\
\hline Postpartum endometritis & 11 & 15.3 \\
\hline Myomectomy & 6 & 18.6 \\
\hline Pelvic surgery & 1 & 10.2 \\
\hline Manual removal of placenta & 1 & 1.7 \\
\hline Total responses & 68 & 1.7 \\
\hline
\end{tabular}

Multiple responses, Total number of respondents were 59, 59 were used as denominator to obtain the frequency. The multiple responses accounts for the total percentage that is more than $100 \%$

Table 5 shows that all the patients had HSG for diagnosis and majority of them had partial intrauterine adhesion $(51,86.4 \%)$. Of the 59 patients in this study only 8 patients had the privilege of having hysteroscopy.
Hysteroscopic grading of the intra-uterine adhesions amongst these 8 patients that had hysteroscopic adhesiolysis revealed that 4 each had mild and severe types respectively.

Table 5: Grading of adhesions and methods of adhesiolysis.

\begin{tabular}{|c|c|c|}
\hline $\begin{array}{l}\text { Grading of adhesion } \\
\text { (HSG) }\end{array}$ & Frequency & Percentage \\
\hline Partial adhesion & 51 & 86.4 \\
\hline Total adhesion & 8 & 13.6 \\
\hline Total & 59 & 100.0 \\
\hline \multicolumn{3}{|c|}{ Hysteroscopic involvement of the cavity $(n=8)$} \\
\hline $1 / 3$ & 4 & 50.0 \\
\hline Up to $2 / 3$ & 4 & 50.0 \\
\hline Total & 8 & 100.0 \\
\hline \multicolumn{3}{|c|}{ Methods of adhesiolysis } \\
\hline Hysteroscopic & 8 & 13.6 \\
\hline Blind & 51 & 86.4 \\
\hline Total & 59 & 100.0 \\
\hline
\end{tabular}

Majority of patients $(25,42.4 \%)$ had restoration of normal menses following adhesiolysis, as shown in Table 6. However, following treatment, 6 women $(10.2 \%)$ of the population achieved pregnancy and only 3 women $(5.1 \%)$ have term birth (Tables 7$)$.

Table 6: Menstrual outcome after 3 months following adhesiolysis.

\begin{tabular}{|lll|}
\hline Outcome & Frequency & Percentage \\
\hline Loss to follow up & 8 & 13.6 \\
\hline No change & 6 & 10.1 \\
\hline $\begin{array}{l}\text { Restoration of normal } \\
\text { menstrual flow }\end{array}$ & 25 & 42.4 \\
\hline Partial improvement & 20 & 33.9 \\
\hline Total & 59 & 100.0 \\
\hline
\end{tabular}

Table 7: Obstetric outcome after a year of adhesiolysis.

\begin{tabular}{|lll|}
\hline Obstetric outcome & Frequency & Percentage \\
\hline Loss to follow up & 13 & 22.0 \\
\hline None & 40 & 67.8 \\
\hline Miscarriage & 3 & 5.1 \\
\hline Term birth & 3 & 5.1 \\
\hline Total & 59 & 100.0 \\
\hline
\end{tabular}

Table 8: Association between the method of adhesiolysis and menstrual outcome.

\begin{tabular}{|c|c|c|c|c|c|c|c|c|}
\hline \multirow[t]{2}{*}{ Method of adhesiolysis } & \multicolumn{2}{|c|}{ No change } & \multicolumn{2}{|c|}{ Partial improvement } & \multicolumn{2}{|c|}{ Restoration of normal flow } & \multirow{2}{*}{\multicolumn{2}{|c|}{$X^{2} \quad P$-value }} \\
\hline & $\mathbf{N}$ & $\%$ & $\mathbf{n}$ & $\%$ & $\mathbf{n}$ & $\%$ & & \\
\hline Hysteroscopic & 1 & 12.50 & 4 & 50.00 & 3 & 37.50 & 0.7 & 0.721 \\
\hline Blind & 13 & 25.50 & 21 & 41.20 & 17 & 33.30 & & \\
\hline \multicolumn{9}{|c|}{ Hysteroscopic involvement } \\
\hline $1 / 3$ & 0 & - & 1 & 25.00 & 3 & 75.00 & & 0.082 \\
\hline Up to $2 / 3$ & 1 & 25.00 & 3 & 75.00 & 0 & - & & \\
\hline
\end{tabular}


Table 8 showed that there was no statistically significant difference between those who had blind adhesiolysis and those who had hysteroscopic adhesiolysis.

\section{DISCUSSION}

The incidence of intrauterine adhesion was found to be $1.6 \%$ in this study which was lower than the incidence reported in Jos $(6.7 \%)$ and Lagos $(4.3 \%)$ but similar to the study carried out in Ilorin $(1.3 \%))^{7-9}$ Majority of the patients with intrauterine adhesion were within the ages of 25-39 years. This was similar to findings from studies carried out in other parts of Nigeria. ${ }^{6-11,13}$ The majority of the women were of low parity as in the studies carried out in Lagos and Federal capital Teritery, Nigeria and this shows that intrauterine adhesion can be associated with infertility. ${ }^{6,20}$ The incidence of intrauterine adhesion was higher among women with tertiary level of education. This was in contrast with the study carried out in lagos. ${ }^{6}$

The relation between intrauterine adhesions, menstrual irregularities and infertility cannot be over emphasized. It has been shown by other studies in Nigeria and reflected in this study that a good percentage of the patients presented with menstrual irregularity..$^{12,20,21}$ Four of the patients had no menstrual irregularity and were only discovered during the course of investigation for infertility and this was similar to the study carried out in national hospital Abuja. ${ }^{6}$ This further emphasizes that a high index of suspicion is needed to make a diagnosis in some cases. ${ }^{13}$

Dilatation and curettage of a recently pregnant uterus play a major role in the development of intrauterine adhesions in several studies and also demonstrated in this study. ${ }^{6,11-13,22}$ This may be attributed to the high incidence of illegal abortion in our environment. ${ }^{12,23}$ Caesarean section was the second leading cause of intrauterine adhesion in this study. This is similar to studies done in Maiduguri, Kano and Lagos where the main indication for the caesarean section was prolonged or obstructed labour. This is likely to be on the increase as the caesarean section rates go up. ${ }^{24,25}$ It is said that a combination of ischemia and inflammation following surgical trauma constitute the main trigger for the development of intrauterine adhesion. However, infection is also a mitigating agent in its development. ${ }^{12,15,22}$

All cases were diagnosed with hysterosalpingogram which has been the most widespread diagnostic tool historically and in similar studies elsewhere. ${ }^{12,13,22}$ It is cost effective and readily available in our facility but it is relatively crude and has a high rate of giving false positive results. ${ }^{22}$ Superior to this is hysteroscopy which gives real time view of the uterine cavity allowing meticulous definition of the site, extent and character of any adhesion. ${ }^{22}$ It is the gold standard in the diagnosis and treatment of intrauterine adhesion. However, a major drawback is its cost and logistics of trained personnel for the procedure.
All patients who had adhesiolysis irrespective of the method, had Foleys catheter insertion and hormonal therapy for 3 cycles in order to promote endometrial regeneration, which was similar to the approach in Maiduguri. ${ }^{12}$ Restoration of menses was seen in $42.4 \%$ and $33.9 \%$ had partial improvement of menses which was similar to studies carried out in Maiduguri (45.5\%), Abuja (47.9\%) but lower than $81.4 \%$ in Benin. . $^{6,21}$ Multiple adhesiolysis in the patients in Benin could explain this high rate. ${ }^{21}$ Pregnancy rates of $10.2 \%$ was similar to the $11.3 \%$ recorded in National Hospital Abuja but lower than $27.3 \%$ achieved in Maiduguri. ${ }^{6,12}$ There was no statistical difference in outcome between patient who had blind or hysteroscopic adhesiolysis. This may be as a result of most of the patients having partial adhesions.

\section{CONCLUSION}

Intrauterine Adhesion is a condition with high impact on female reproduction. Dilatation and curettage is still a major predisposing factor in the development of intrauterine Adhesions in our environment. Blind adhesiolysis still has its place in its management in developing countries.

\section{Funding: No funding sources}

Conflict of interest: None declared

Ethical approval: The study was approved by the Institutional Ethics Committee

\section{REFERENCES}

1. Asherman JG. Amenorrhoea Traumatic (atretica). J Obstet Gynecol Br Emp. 1948;55(2):23-30.

2. Balen A. Polycystic ovary syndrome and Secondary Ammenorrhoea. Edmonds KD, eds. Dewhurst's textbook of obstetrics and gynaecology. WileyBlackwell companies; 2011:513-33.

3. Berman JM. Intrauterine adhesions. Semin Reprod Med. 2008;26:349-55.

4. Giwa-Osagie OF, Emuveyan EE. Evaluation of secondary Amenorrhoea. Nig Med Pract. 1968;7:7983.

5. Otubu JA, Olanrewaju RS. Hysteroscopy in infertile Nigerian women. Afr J Med Sci. 1989;18:117-20.

6. Efena RE, Agustine $\mathrm{CU}$ and Ugochukwu VO. Clinical and demographic characteristics of women with intrauterine adhesion in Abuja, Nigeria. Obstet Gynaecol Int. 2012:435475.

7. Abiodun OM, Balogun OR, Fawole AA. Aetiology, clinical features and treatment outcome of intrauterine adhesion in Ilorin, Central Nigeria. West Afr J Med. 2007;26:298-301.

8. Otubu JAM, Olanrewaju RS. Ashermans syndrome: experience in Jos University Teaching Hospital. Trop J Obstet Gynaecol. 1993;10:30-2.

9. Ogedengbe OK, Ogunmokun AA. The trend of intrauterine adhesions in Lagos Nigeria. Trop J Obstet Gynaecol. 1999;16:57-60. 
10. Toaff R, Ballas S. Traumatic hypomenorrhoea: Amenorrhoea (Asherman's syndrome). Fertil Steril. 1978;30:379-87.

11. Adesiyun AG, Zayyan MS, Eka A, Williams IO, Ojabo A. Clinical and investigative correlates of etiologic risk factors on treatment outcome of intrauterine adhesion in women with infertility: a descriptive study. Open J Obstet Gynaecol. 2014;4:95-9.

12. Kwari SD, Idrisa A. Intrauterine adhesiolysis at the University of Maiduguri Teaching Hospital, Maiduguri, Nigeria: a 3-year review. Trop J Obstet Gynaecol. 2011;28:54-7.

13. Gaya SA, Adamu IS, Yakasai IA, Abubakar S. Review of intrauterine adhesiolysis at the Aminu Kano Treaching Hospital, Kano, Nigeria. Ann Afr Med. 2012;11:65-9.

14. Abbott JA, Deans R, Kingston A, Vancaillie TG. The management of intrauterine synechiae. Curr Opin Obstet Gynecol. 2009;21:335-41.

15. Yu D, Wong YM, Cheong Y, Xia E, Li TC. Asherman's syndrome-one century later. Fertil Steril. 2008;89:759-79.

16. March CM. Intrauterine adhesions. Obstet Gynaecol Clin North Am. 1995;22:491-505.

17. Al-Inany H. Intrauterine adhesions. An update. Acta Obstet Gynaecol Scand. 2001;80:986-93.

18. Toaff R. Amenorrhoea hypomenorrhoea traumatic (syndrome di Asherman). Ani de la societa Italiana di Ginecol. 1962;49:258.

19. Wamsteker K, DeBlok S. Diagnostic hysteroscopy. Technique and documentation. Saunder, Sutton C and Daimond M, eds. Endoscopic surgery for gynaecologists, London. 1993;263-76.

20. Ogedengbe OK, Giwa Osagie OF, Adedeji OF, Oyeyinka O. Intrauterine adhesions in Lagos Nigeria. J Obstet Gynaecol. 1991;11:134-6.

21. Orhue AAE, Aziken ME, Igbefoh JO. A comparism of two adjunctive treatments for intrauterine adhesions following lysis. Int $\mathbf{J}$ Gynaecol Obstet. 2003;82:49-56.

22. Conforti A, Alviggi C, Mollo A, De Placido G, Magos A. The management of Asherman syndrome: a review of literature. Reprod Biol Endocrinol. 2013;11:118.

23. Ozumba B, Ezegwui H. Intrauterine adhesions in an African population. Int $\mathrm{J}$ Gynaecol Obstet. 2002;7:37-38.

24. O'Neill SM, Agerbo E, Khashan AS, Kearney PM, Henriksen TB, Mortensen LC. Trial of labour or elective repeat caesarean section and the risk of neonatal and infant mortality: a population registerbased cohort study. J Epidemiol Community Health. 2015;69:36-7.

25. Geidam AD, Audu BM, Kawuwa BM, Obed JY. Rising trend and indications of caesarean sections at the university of Maiduguri teaching hospital, Nigeria. Ann Afr Med. 2009;8:127-32.

Cite this article as: Opadiran RO, Isah AD, Agida ET, Adewole N. Fetal Outcome of intrauterine adhesion management at a Nigerian tertiary hospital: a five-year review. Int J Reprod Contracept Obstet Gynecol 2018;7:375-9. 